\title{
An investigation of the presence of specific anaerobic species in necrotic primary teeth
}

Genara Brum Gomes ${ }^{(a)}$ Rafael Sarkis-Onofre ${ }^{(b)}$ Maria Laura Menezes Bonow(c) Adriana Etges ${ }^{(b)}$ Rogério Castilho Jacinto(b)

(a) Department of Orthodontics and Pediatric Dentistry, School of Dentistry, Univ Federal de Minas Gerais - UFMG, Belo Horizonte, MG, Brazil.

(b) Department of Semiology and Clinics, School of Dentistry, Univ Federal de Pelotas - UFPel, Pelotas, RS, Brazil.

(c) Department of Social and Preventive Dentistry, School of Dentistry, Univ Federal de Pelotas - UFPel, Pelotas, RS, Brazil.

Declaration of Interests: The authors certify that they have no commercial or associative interest that represents a conflict of interest in connection with the manuscript.

Corresponding Author: Rogério Castilho Jacinto

E-mail: rogeriocastilho@hotmail.com

Submitted: Sep 26, 2012

Accepted for publication: Dec 21, 2012

Last revision: Jan 18, 2013

\begin{abstract}
Different microbial identification methods have shown that the microbial community profiles in endodontic infections are diverse and assorted. The aim of this study was to evaluate the frequency of selected endodontic pathogens in the pulp chambers (PCs) and root canals (RCs) of infected primary teeth using PCR methods. Paired PC and RC samples were collected from 15 subjects and analyzed by PCR for the presence of Filifactor alocis, Fusobacterium nucleatum, Parvimonas micra, Porphyromonas endodontalis, Porphyromonas gingivalis, Prevotella intermedia, Prevotella nigrescens, Prevotella tannerae, Tanerella forsythia, Treponema denticola, and Treponema socranskii. The frequency of each species was determined in the PC and RC of each case. The species most frequently detected in PCs were P. nigrescens $(86.7 \%)$, P. gingivalis (73.3\%), and F. alocis (73.3\%). Of the PC samples, $13.3 \%$ contained P. micra and T. denticola, and $6.7 \%$ contained T. forsythia. The species most frequently detected in RCs were $P$. gingivalis $(100 \%)$ and P. nigrescens (93.3\%). P. tannerae, P. micra, and T. denticola were found in $40 \%$ of the RC samples; T. forsythia was found in $26.7 \%$ of the RC samples. The "red complex", which comprises P. gingivalis, T. denticola, and T. forsythia, was not found in the PC of any tooth but was found in $30 \%$ of the RC samples. The detection of $P$. nigrescens in the PC was statistically associated with the presence of $P$. nigrescens in the $\mathrm{RC}(\mathrm{p}=0.04)$. The results suggest high heterogeneity among the samples, even among those from the same subject.
\end{abstract}

Descriptors: Tooth, Deciduous; Endodontics; Bacteria, Anaerobic; Polymerase Chain Reaction.

\section{Introduction}

Endodontic infections of primary teeth are related to bacterial incursion and multiplication in the pulp chamber (PC) and root canals (RCs). Depending on the virulence and number of microorganisms present in RCs, acute or chronic inflammation may be established in the periapical region..$^{1,2}$

In infected primary teeth, lesions normally develop in the furcation area instead of around the tooth apex, which could be related not only to the high incidence of accessory furcation canals ${ }^{3}$ but also to infections with certain bacteria at these sites. However, few studies have been performed using molecular methods to identify the presence of anaero- 
bic bacteria in RCs of necrotic primary teeth. ${ }^{4,5}$ In addition, there are no reports in the literature that compare the microbial composition of PCs with that of RCs of infected primary teeth. Many anaerobic microorganisms are difficult to culture and identify precisely; thus, molecular methods have been used to identify microorganisms from endodontic infections. ${ }^{6}$

The aim of this study was to detect the presence of Filifactor alocis, Fusobacterium nucleatum, Parvimonas micra, Porphyromonas endodontalis, Porphyromonas gingivalis, Prevotella intermedia, Prevotella nigrescens, Prevotella tannerae, Tanerella forsythia, Treponema denticola, and Treponema socranskii in the PCs and RCs of primary teeth, as well as to compare the prevalence of these species in both environments.

\section{Methodology Study sample}

The present research was approved by the Research Ethics Committee of the Pelotas Dental School (protocol no. 126/2009, Federal University of Pelotas, Brazil), and informed consent agreements were obtained from the parents of the children involved in this study. Fifteen subjects ranging from 3 to 8 years of age who presented with pulp necrosis in primary molars were selected at the Department of Pediatric Dentistry (UFPel). The following information was recorded for each patient, according to Jacinto et al.: ${ }^{7}$

- age,

- gender,

- previous episodes of pain,

- presence of tooth mobility,

- sinus tract,

- presence of swelling on periodontal tissues,

- presence or absence of periapical/interradicular bone resorption,

- RC status during sampling (such as dry or wet canals), and

- presence or absence of a foul odor.

The selected teeth had not received previous endodontic treatment. Children who received antibiotic treatment within the preceding 3 months or who presented with systemic diseases were excluded from the study. Teeth with exposure of the PC to the oral cavity before pulp management and teeth with internal resorption were excluded from the study. All of the teeth had intact roots or resorption of less than one-third of the physiological root. In addition, all selected molars had clinical crowns that permitted effective rubber dam isolation and only occlusal caries, without involvement of proximal surfaces, and to an extent that did not expose the PC to the oral cavity. There was an absence of a history of trauma associated with the selected teeth and an absence of periodontal involvement.

\section{Clinical procedures}

Clinical procedures and sample collection procedures were adapted from Jacinto et al. ${ }^{7}$ After application of local anesthesia, antisepsis of the child's oral cavity was performed with $0.12 \%$ chlorhexidine gluconate. The involved tooth received coronary polishing and was isolated with a rubber dam. The tooth surfaces, clamp, rubber dam, and arch were disinfected with sterile swabs soaked first in 30\% hydrogen peroxide followed by $2.5 \%$ sodium hypochlorite for 30 seconds each, and then were neutralized with a sterile $5 \%$ sodium thiosulfate solution. ${ }^{8}$ After disinfection, a sample was taken with a sterile swab from the operational field and was analyzed by PCR. Carious tissues were removed using sterile burs, and preparation for complete access was carried out with an Endo-Z stainless steel bur (Dentsply Maillefer, Ballaigues, Switzerland) at high speed under manual irrigation with sterile $0.9 \%(\mathrm{w} / \mathrm{v})$ sodium chloride until coronal access was gained.

\section{Sample collection}

Samples were taken from the PC of each tooth as follows: a sterile cotton ball moistened in sterile physiologic solution was inserted in the PC and kept in contact with the chamber floor for $60 \mathrm{sec}-$ onds and then transferred to an empty sterile 1.5$\mathrm{mL}$ tube (Axygen, Union City, USA). Then the PC was disinfected with cotton balls soaked in $2.5 \%$ sodium hypochlorite, which was inactivated with $5 \%$ sodium thiosulfate. Afterwards, three sterile absorbent paper points were sequentially placed into 
the full length of the largest canal (palatal canal of maxillary molars and distal canal of mandibular molars) $)^{9}$ for 60 seconds and were then transferred to an empty sterile $1.5-\mathrm{mL}$ tube. If the canal was dry, the paper point was moistened in sterile saline solution before transfer to the tube to ensure viable sample acquisition. The samples were stored at $-80^{\circ} \mathrm{C}$. All teeth involved in the study were endodontically treated after sampling. The technique for primary tooth endodontic treatment followed the American Association of Pediatric Dentistry guidelines,${ }^{10}$ and all teeth were restored with modified glass ionomer resin (Vitremer; 3M-ESPE, St. Paul, USA).

\section{Detection of target species by PCR}

PCR reactions were conducted according to Montagner et al. ${ }^{11}$ Bacterial DNA was extracted with the PureLink Genomic DNA Mini kit (Invitrogen, Carlsbad, USA). The universal bacterial primers $\mathrm{EuF}$ and EuR, which are directed to the $16 \mathrm{~S}$ rRNA gene, were used to verify the presence of bacterial DNA in the samples, and specific primers were used to investigate specific species: F. alocis, F. nucleatum, $P$. micra, $P$. endodontalis, $P$. gingivalis, $P$. intermedia, $P$. nigrescens, $P$. tannerae, T. forsythia, $T$. denticola, and T. socranskii (Table 1). For each sample from the PC and RC, the PCR reaction was performed with $1.5 \mu \mathrm{L}$ of extracted DNA added to the reaction mixture. The mixture consisted of $2.5 \mu \mathrm{L}$ $10 \times$ reaction buffer, $0.75 \mu \mathrm{L} 100 \mathrm{mM}$ forward primer, $0.75 \mu \mathrm{L} 100 \mathrm{mM}$ reverse primer, $0.5 \mu \mathrm{L} 25 \mathrm{mM}$ dNTPs, $1.25 \mu \mathrm{L} 25 \mathrm{mM} \mathrm{MgCl}, 0.125 \mu \mathrm{L} 5 \mathrm{U} / \mathrm{mL}$ Taq polymerase, and $17.625 \mu \mathrm{L}$ milli-Q water.

The steps of the PCR cycle included an initial denaturation $\left(95^{\circ} \mathrm{C}, 2\right.$ minutes); 36 cycles of denaturation $\left(94^{\circ} \mathrm{C}, 30\right.$ seconds), annealing (temperature according to Table 1, 1 minute), and extension $\left(72^{\circ} \mathrm{C}, 2\right.$ minutes $)$; and a final extension $\left(72^{\circ} \mathrm{C}, 10\right.$ minutes). PCR reactions were performed in a thermocycler (Mastercycler Family; Brazil Eppendorf;

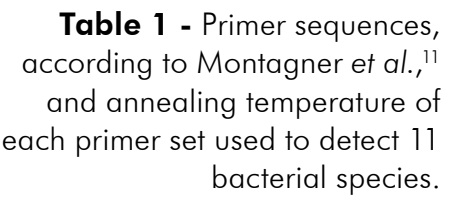

\begin{tabular}{|c|c|c|c|}
\hline Species & Sequence & Size (bp) & A.T. \\
\hline $\begin{array}{l}\text { Non-specific } \\
\text { (EuF/EuR) }\end{array}$ & $\begin{array}{l}\text { 5' TCC TAC GGG AGG CAG CAG T 3' } \\
\text { 5' GGA CTA CCA GGG TAT CTA ATC CTG TT 3' }\end{array}$ & 466 & $60^{\circ} \mathrm{C}$ \\
\hline F. alocis & $\begin{array}{l}\text { 5' AAA CCC ATC TCT GAG TTC TTC TTC 3' } \\
\text { 5' ATG CCA ACT TGA CGT TAA AT 3' }\end{array}$ & 594 & $60^{\circ} \mathrm{C}$ \\
\hline F. nucleatum & $\begin{array}{l}\text { 5' ATT GTG GCT AAA AAT TAT AGT T 3' } \\
\text { 5' ACC CTC ACT TTG AGG ATT ATA G 3' }\end{array}$ & 1000 & $55^{\circ} \mathrm{C}$ \\
\hline P. micra & $\begin{array}{l}\text { 5' AGA GTT TGA ATC CTG GCT CAG 3' } \\
\text { 5' ATA TCA TGC GAT TCT GTG GTC TC 3' }\end{array}$ & 207 & $60^{\circ} \mathrm{C}$ \\
\hline P. endodontalis & $\begin{array}{l}\text { 5' GCT GCA GCT CAA CTG TAG TC 3' } \\
\text { 5' CCG CTT CAT GTC ACC ATG TC 3' }\end{array}$ & 672 & $58^{\circ} \mathrm{C}$ \\
\hline P. gingivalis & $\begin{array}{l}\text { 5' AGG CAG CTT GCC TAG AGT CGG 3' } \\
\text { 5' ACT GTT AGC AAC TAC CGA TGT 3' }\end{array}$ & 404 & $58^{\circ} \mathrm{C}$ \\
\hline P. intermedia & $\begin{array}{l}\text { 5' TTT GTT GGG GAG TAA AGC GGG 3' } \\
\text { 5' TCA ACA TCT CTG TAT CCT GCG T 3' }\end{array}$ & 575 & $58^{\circ} \mathrm{C}$ \\
\hline P. nigrescens & $\begin{array}{l}\text { 5' ATG AAA CAA AGG TTT TCC GGT AAG 3' } \\
5^{\prime} \text { CCC ACG TCT CTG TGG GCT GCG A 3' }\end{array}$ & 804 & $58^{\circ} \mathrm{C}$ \\
\hline P. tannerae & $\begin{array}{l}\text { 5' CTT AGC TTG CTA AGT ATG CCG 3' } \\
\text { 5' CAG CTG ACT TAT ACT CCC G 3' }\end{array}$ & 550 & $55^{\circ} \mathrm{C}$ \\
\hline T. forsythia & $\begin{array}{l}\text { 5' TGC TTC AGT AGT TAT ACC T 3' } \\
\text { 5' TGC TTC AGT GTC AGT TAT ACC T 3' }\end{array}$ & 641 & $56^{\circ} \mathrm{C}$ \\
\hline T. denticola & 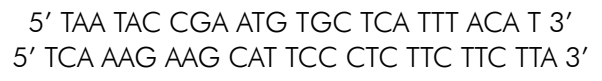 & 316 & $60^{\circ} \mathrm{C}$ \\
\hline T. socranskii & $\begin{array}{c}\text { 5' GAT CAC TGT ATA CGG AAG GTA GAC A 3' } \\
\text { 5' TAC ACT TAT TCC TCG GAC AG 3' }\end{array}$ & 288 & $56^{\circ} \mathrm{C}$ \\
\hline
\end{tabular}

A.T.: annealing temperature; bp: base pairs. 


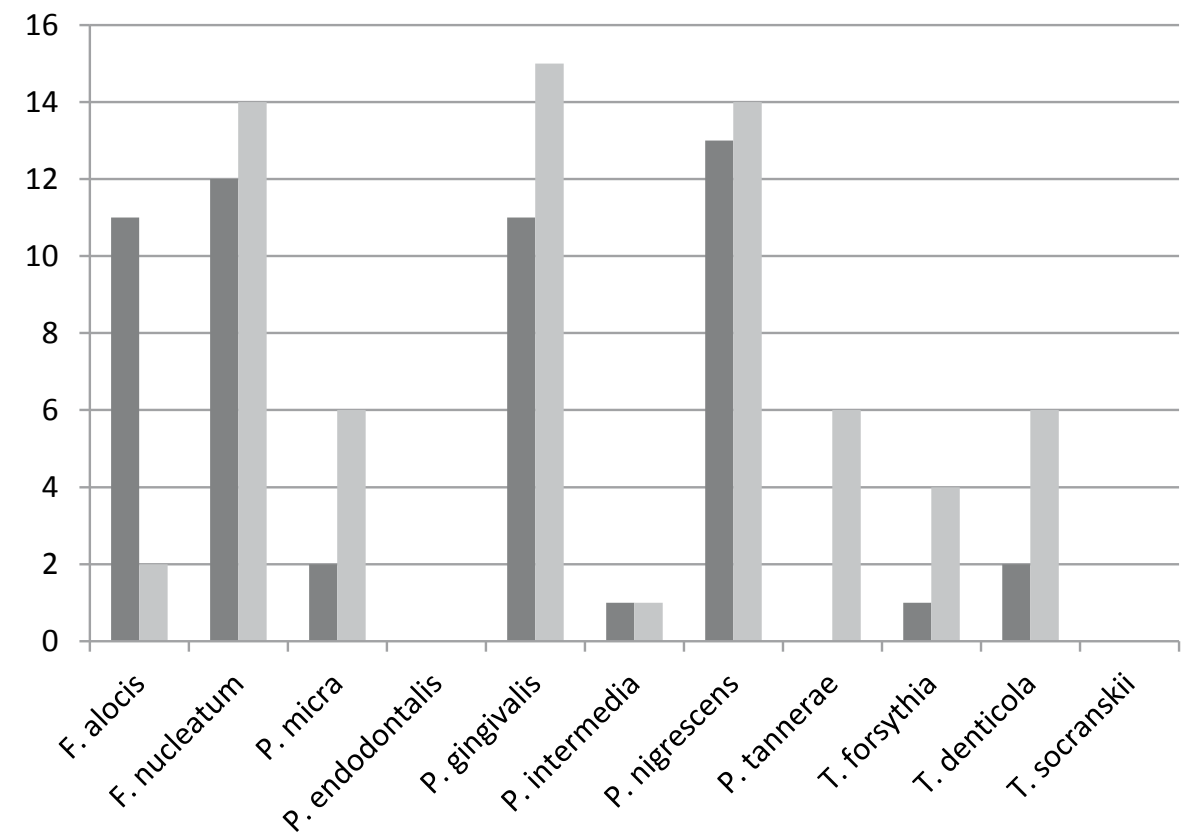

Figure 1 - Detection frequency of each bacterial species investigated in 15 PC samples and 15 RC samples.

- PC = Pulp Chamber

RC $=$ Root Canal
São Paulo, Brazil). Aliquots of extracted DNA from ATCC strains and aliquots of ultrapure water were used as positive and negative controls, respectively. The reference strains were as follows:

- F. alocis ATCC 35896,

- F. nucleatum ATCC 25586,

- P. micra ATCC 33270,

- P. endodontalis ATCC 35406,

- $P$. gingivalis ATCC W83,

- P. intermedia ATCC 25611,

- P. nigrescens ATCC 33563,

- P. tannerae ATCC 51259, and

- T. forsythia ATCC 43037.

PCR products were analyzed by $1 \%$ agarose gel electrophoresis stained with GelRed (Biotium, Hayward, USA) and viewed under ultraviolet light transillumination (Major Science, Saratoga, USA). Detection was based on the presence of clear bands of the expected molecular size using a 50-bp DNA ladder (Invitrogen Corporation).

\section{Statistical analysis}

The data collected for each subject were entered into a spreadsheet and statistically analyzed using SPSS for Windows (SPSS Inc., Chicago, USA). Fisher's exact test was used to test the null hypoth- esis that there was no statistically significant association between the presence of specific species in the PCs and RCs. The level of significance was 5\% $(\mathrm{p}<0.05)$.

\section{Results}

All samples were positive for the presence of bacterial DNA when the primers directed to the $16 \mathrm{~S}$ rRNA gene were used. Figure 1 shows the frequency of the 11 species found by species-specific $16 \mathrm{~S}$ rRNA-directed PCR among the 15 samples from both the PCs and RCs. In general, more species were detected in the RC (mean, 3.6) than in the PC (mean, 2.7). The highest number of species found in the same tooth was seven, and all teeth presented at least one of the target species, either in the PC or in the RC. The species most frequently detected in the PC were $P$. nigrescens $(86.7 \%), P$. gingivalis $(73.3 \%)$, and F. alocis (73.3\%). Of the PC samples, $13.3 \%$ contained P. micra and T. denticola, and $6.7 \%$ contained $T$. forsythia. The species most frequently detected in RC samples were $P$. gingivalis $(100 \%)$ and $P$. nigrescens (93.3\%). P. tannerae, $P$. micra, and T. denticola were found in $40 \%$ of RC samples; T. forsythia was found in $26.7 \%, F$. alocis in $13.3 \%$, and P. intermedia in $6.7 \%$ of RC samples. The species $T$. socranskii and $P$. endodontalis were 
not detected in RC or PC samples.

The concomitant presence of microbial species in PC and RC paired samples occurred in some cases. The detection of $P$. nigrescens in the PC was statistically associated with the presence of $P$. nigrescens in the RC ( $\mathrm{p}=0.04)$. Interradicular bone resorption was detected in nine cases; the most frequent species that were associated with these cases were $F$. alocis and $P$. nigrescens in the $\mathrm{PC}$ and $\mathrm{P}$. gingivalis and $P$. nigrescens in the RC.

There was no statistically significant association between the presence of bacteria and clinical signs and symptoms.

The simultaneous presence of $P$. gingivalis, $T$. forsythia, and $T$. denticola, which together form the "red complex", ${ }^{12}$ was not found in the PC of any teeth but was found in the RC in three cases.

\section{Discussion}

The RCs of primary teeth with necrotic pulp and chronic interradicular/apical lesions present a high number of bacterial species and often exhibit polymicrobial infection with a high prevalence of anaerobic bacteria. ${ }^{2,13,14}$ In the present study, bacterial DNA was detected in all PC and RC samples investigated. Samples collected from the operational field were DNA-free, confirming that the DNA detected in the PC and RC samples did not result from trace external contamination.

The most commonly isolated genera in endodontic infections include Fusobacterium, Prevotella, and Porphyromonas spp. ${ }^{15}$ In the present study, $P$. gingivalis was detected in all RCs investigated, and species such as $P$. nigrescens were also highly detected. Tavares et al. ${ }^{4}$ detected $P$. intermedia in $96.9 \%$ of the samples from the RC system of primary teeth exhibiting pulp necrosis with or without radiographically detectable interradicular bone resorption, followed by other obligate anaerobes, such as $P$. nigrescens, T. forsythia, $P$. denticola, and F. nucleatum ss vincenti. In a study by Ruviere et al., ${ }^{16}$ Campylobacter rectus, T. denticola, and Gemella morbillorum were the most prevalent taxa, whereas Cogulu et al..$^{5}$ found that T. denticola and P. gingivalis were the most prevalent species.

The most commonly isolated Gram-positive coc- ci from RCs of primary teeth include Peptostreptococcus spp. ${ }^{17}$ The present study found the presence of $P$. micra, which formerly belonged to the genus Peptostreptococcus, in $40 \%$ of the RCs. P. micra is associated with the pathogenesis of $P$. gingivalis in endodontic abscesses..$^{18}$ Ruvieri et al. ${ }^{16}$ detected $P$. micra in $26 \%$ of the primary teeth examined, whereas Cogulu et al. ${ }^{5}$ detected this species only in $3 \%$ of primary teeth exhibiting periapical/interradicular radiolucency. The differences in these results could be attributed to the different sets of primers used or the different features of the samples.

Socransky et al. ${ }^{12}$ stratified the periodontal microbiota into groups or complexes. The "red complex" is part of the climax community in biofilms and comprises species that are considered oral pathogens, namely $P$. gingivalis, $T$. denticola, and $T$. forsythia. These species were found in association in three RC samples in this study.

The occurrence of endodontic symptomatology may be the result of an increased virulence of microorganisms. Cogulu et al. ${ }^{5}$ found that T. denticola and Enterococcus faecalis are highly associated with previous pain and that $P$. gingivalis is associated with tenderness to percussion in primary teeth. However, the different incidences of the microorganisms detected in the present report, as compared with those of other studies that used different methods for microbial identification, suggest that, similar to infections in RCs of permanent teeth, the microbial composition of endodontic infections of primary teeth is heterogeneous. This finding confirms that it is not possible to attribute the etiology of these pathologies to specific microorganisms.

Even though DNA sequence analysis is the gold standard in microbial identification, PCR also represents a sensitive, fast, and accessible method for the study of endodontic bacteria. ${ }^{19}$ Therefore, PCR was used in the present study. A disadvantage of this method is that by targeting specific bacteria, it does not allow a broad examination of the microbial profiles related to these particular PCs and RCs. However, based on our results, it is possible to speculate that PCs and RCs exhibit different microbial profiles. Furthermore, the anaerobes investigated generally had a higher prevalence in the RCs than in the PCs, possi- 
bly because of factors such as the gradual decrease in oxygen tension in RCs, together with the nutritional needs of microorganisms and the food chain that influence the process of bacterial succession from the saccharolytic cariogenic flora in the PCs to a more anaerobic and proteolytic flora in the RCs.

The ample medullar bone spaces of children favor infection dissemination. In rare situations, bacteria and their toxic products that enter the trabecular bone in the interradicular area of primary teeth $^{20}$ and induce acute inflammation and pus formation $^{21}$ might lead to a spread of these dental abscesses, threatening the life of the child. Another and more likely consequence of pulp necrosis in primary teeth is that these infections may potentially affect the permanent tooth germ. ${ }^{22}$ In the present study, no statistical association was found between specific species and the presence of radiolucent interradicular areas. When analyzing 79 patients with infected primary teeth, Cogulu et al..$^{5}$ found that $T$. denticola and E. faecalis are highly associated with periapical radiolucency. These differences in results could be attributed to sample size. Furthermore, in cases with interradicular radiolucency in the present

\section{References}

1. Tani-Ishii N, Wang CY, Tanner A, Stashenko P. Changes in root canal microbiota during the development of rat periapical lesions. Oral Microbiol Immunol. 1994 Jun;9(3):129-35.

2. Toyoshima Y, Fukushima H, Inoue JI, Sasaki Y, Yamamoto K, Katao H, et al. [A bacteriological study of periapical pathosis on deciduous teeth]. Shoni Shikagaku Zasshi. 1988;26(3):44958. Japanese.

3. Wrbas KT, Kielbassa AM, Hellwig E. Microscopic studies of accessory canals in primary molar furcations. ASDC J Dent Child. 1997 Mar-Apr; 64(2):118-22.

4. Tavares WL, Brito LCN, Teles RP, Massara ML, Ribeiro Sobrinho AP, Haffajee AD, et al. Microbiota of deciduous endodontic infections analysed by MDA and Checkerboard DNA-DNA hybridization. Int Endod J. 2011 Mar;44(3):225-35.

5. Cogulu D, Uzel A, Oncag O, Eronat C. PCR-based identification of selected pathogens associated with endodontic infections in deciduous and permanent teeth. Oral Surg Oral Med Oral Pathol Oral Radiol Endod. 2008 Jun;106(3):443-9.

6. Fouad AF, Barry J, Caimano M, Clawson M, Zhu Q, Carver $\mathrm{R}$, et al. PCR-based identification of bacteria associated with endodontic infections. J Clin Microbiol. 2002 Sep;40(9):322331. study, P. gingivalis was found in five $\mathrm{PC}$ and nine $\mathrm{RC}$ samples, and P. nigrescens was found in six PC and eight RC samples. The pathogenesis of these species, especially when associated with other anaerobes, may influence bone loss in the interradicular area.

\section{Conclusion}

The role of bacteria in lesion pathogenesis is undeniable, although modern diagnostic techniques have not identified a single causative pathogen. The results suggest a high bacterial heterogeneity among PCs and RCs. Strict anaerobes were frequently detected in PC and RC samples, but specific anaerobic species were not associated with interradicular radiolucent lesions or other signs and symptoms of infection. Therefore, studies comprising a larger number of cases and a wider range of species are necessary to investigate these associations.

\section{Acknowledgements}

We would like to thank the CCDB - Pelotas Dental School, Federal University of Pelotas and CNPq (483809/2007-1).

7. Jacinto RC, Montagner F, Signoretti FG, Almeida GC, Gomes BP. Frequency, microbial interactions, and antimicrobial susceptibility of Fusobacterium nucleatum and Fusobacterium necrophorum isolated from primary endodontic infections. J Endod. 2008 Dec;34(12):1451-6.

8. Moller AJ. Microbiological examination of root canals and periapical tissues of human teeth. Methodological studies. Odontol Tidskr. 1966 Dec 20;74(5):Suppl:1-380.

9. Gomes BP, Jacinto RC, Pinheiro ET, Sousa EL, Zaia AA, Ferraz CC, et al. Porphyromonas gingivalis, Porphyromonas endodontalis, Prevotella intermedia and Prevotella nigrescens in endodontic lesions detected by culture and by PCR. Oral Microbiol Immunol. 2005 Aug;20(4):211-15.

10. American Academy of Pediatric Dentistry. Guideline on pulp therapy for primary and young permanent teeth. Pediatr Dent. 2004;26(7 Suppl):115-9.

11. Montagner F, Jacinto RC, Signoretti FG, Sanches PF, Gomes BP. Clustering behavior in microbial communities from acute endodontic infections. J Endod. 2012 Feb;38(2):158-62.

12. Socransky SS, Haffajee AD, Cugini MA, Smith C, Kent RL Jr. Microbial complexes in subgingival plaque. J Clin Periodontol. 1998 Feb;25(2):134-44. 
13. Pazelli LC, Freitas AC, Ito IY, Souza-Gugelmin MC, Medeiros AS, Nelson-Filho P. Prevalence of microorganisms in root canals of human deciduous teeth with necrotic pulp and chronic periapical lesions. Pesqui Odontol Bras. 2003 OctDec;17(4):367-71.

14. Silva LA, Nelson-Filho P, Faria G, Souza-Gugelmin MC, Ito IY. Bacterial profile in primary teeth with necrotic pulp and periapical lesions. Braz Dent J. 2006 Jul;17(2):144-48.

15. Sundqvist G, Johansson E, Sjogren U. Prevalence of blackpigmented bacteroides species in root canal infections. J Endod. 1989 Jan;15(1):13-9.

16. Ruviere DB, Leonardo MR, Silva LA, Ito IY, Nelson-Filho P. Assessment of the microbiota in root canals of human primary teeth by checkerboard DNA-DNA hybridization. J Dent Child (Chic). 2007 May-Aug;74(2):118-23.

17. Yang QB, Fan LN, Shi Q. Polymerase chain reaction-denaturing gradient gel electrophoresis, cloning, and sequence analysis of bacteria associated with acute periapical abscesses in children. J Endod. 2010 Feb;36(2):218-23.
18. Jacinto RC, Gomes BP, Ferraz CC, Zaia AA, Souza Filho FJ. Microbiological analysis of infected root canals from symptomatic and asymptomatic teeth with periapical periodontitis and the antimicrobial susceptibility of some isolated anaerobic bacteria. Oral Microbiol Immunol. 2003 Oct;18(5):285-92.

19. Siqueira Jr JF, Rocas IN. PCR methodology as a valuable tool for identification of endodontic pathogens. J Dent. $2003 \mathrm{Jul} ; 31(5): 333-9$.

20. Tannure PN, Barcelos R, Portela MB, Gleiser R, Primo LG. Histopathologic and SEM analysis of primary teeth with pulpectomy failure. Oral Surg Oral Med Oral Pathol Oral Radiol Endod. 2009 Jul;108(1):e29-33.

21. Nair PN. Pathogenesis of apical periodontitis and the causes of endodontic failures. Crit Rev Oral Biol Med. 2004 Nov 1;15(6):348-81.

22. Cordeiro MM, Rocha MJ. The effects of periradicular inflamation and infection on a primary tooth and permanent successor. J Clin Pediatr Dent. 2005 Spring;29(3):193-200. 